\title{
Tiotropium Attenuates Virus-Induced Pulmonary Inflammation in Cigarette Smoke-Exposed Mice
}

\author{
Hannes Bucher, Matthias J. Duechs, Cornelia Tilp, Birgit Jung, and Klaus J. Erb \\ Immunology \& Respiratory Diseases Research, Boehringer Ingelheim Pharma GmbH \& Co. KG, Biberach an der Riss, Germany \\ Received March 14, 2016; accepted March 16, 2016
}

\begin{abstract}
Viral infections trigger exacerbations in chronic obstructive pulmonary disease (COPD), and tiotropium, a M3 receptor antagonist, reduces exacerbations in patients by unknown mechanisms. In this report, we investigated whether tiotropium has anti-inflammatory effects in mice exposed to cigarette smoke (CS) and infected with influenza virus A/PR/8/34 (H1N1) or respiratory syncytial virus (RSV) and compared these effects with those of steroid fluticasone and PDE4-inhibitor roflumilast. Mice were exposed to CS; infected with $\mathrm{H} 1 \mathrm{~N} 1$ or RSV; and treated with tiotropium, fluticasone, or roflumilast. The amount of cells and cytokine levels in the airways, lung function, and viral load was determined. $\mathrm{NCl}-\mathrm{H} 292$ cells were infected with $\mathrm{H} 1 \mathrm{~N} 1$ or RSV and treated with the drugs. In CS/H1N1-exposed mice, tiotropium reduced neutrophil and macrophage numbers and levels of interleukin-6 (IL-6) and interferon- $\gamma$ (IFN- $\gamma$ ) in the airways and improved lung function. In contrast, fluticasone
\end{abstract}

increased the loss of body weight; failed to reduce neutrophil or macrophage numbers; increased IL-6, KC, and tumor necrosis factor- $\alpha$ (TNF- $\alpha$ ) in the lungs; and worsened lung function. Treatment with roflumilast reduced macrophage numbers, IL-6, and KC in the lungs but had no effect on neutrophil numbers or lung function. In CS/RSV-exposed mice, treatment with tiotropium, but not fluticasone or roflumilast, reduced neutrophil numbers and IL- 6 and TNF- $\alpha$ levels in the lungs. Viral load of $\mathrm{H} 1 \mathrm{~N} 1$ and RSV was significantly elevated in CS/virus-exposed mice and $\mathrm{NCl}-\mathrm{H} 292$ cells after fluticasone treatment, whereas tiotropium and roflumilast had no effect. In conclusion, tiotropium has anti-inflammatory effects on CS/virus-induced inflammation in mice that are superior to the effects of roflumilast and fluticasone. This finding might help to explain the observed reduction of exacerbation rates in COPD patients.

\section{Introduction}

Worldwide, approximately 65 million people suffer from chronic obstructive pulmonary disease (COPD), a major health and economic burden and one of the leading causes of premature death in both current and former smokers (Stockley et al., 2009; Dance, 2012; Mohamed Hoesein et al., 2013). Generally, COPD is associated with increased neutrophil numbers and high levels of pro-inflammatory cytokines, such as tumor necrosis factor- $\alpha$ (TNF- $\alpha$ ), interleukin (IL)-6, IL-8, interferon- $\gamma$ (IFN- $\gamma$ ), and IL- $1 \beta$ in the airways (Barnes, 2008). The major clinical manifestations include chronic bronchitis, airflow limitation, and emphysema (Jeffery, 2000; Rabe et al., 2007). Worsening of symptoms occurs when COPD patients experience exacerbations, which dramatically increase morbidity and mortality (Sapey and Stockley, 2006). Important triggers of exacerbations are viral infections of the respiratory tract (Wedzicha and Seemungal, 2007).

Inhaled corticosteroids (ICS), for example, fluticasone, are frequently used to reduce inflammation in COPD patients (Barnes, 2002; Park et al., 2012); however, the role of ICS in

Hannes Bucher and Matthias J. Duechs contributed equally to this work. dx.doi.org/10.1124/jpet.116.232009.
COPD treatment is controversial. Studies have shown that ICS treatment does not attenuate neutrophil-driven inflammation and disease progression (Barnes, 2002; Rich, 2005; Park et al., 2012). Furthermore, adverse effects have been reported to be associated with ICS treatment, including an increased risk for candidiasis, cataracts, and fractures (Park et al., 2012). In addition, a large randomized, double-blind trial comprising 6112 patients revealed an increased risk of pneumonia (the TORCH study), and the withdrawal of ICS did not adversely affect the rate of exacerbations in COPD patients (the WISDOM study) (Calverley et al., 2007; Park et al., 2012; Magnussen, et al., 2014).

Another approach to control inflammation in COPD patients is treatment with roflumilast (Rabe, 2011; Oba and Lone, 2013). Roflumilast acts through blocking phosphodiesterase-4 (PDE4), an enzyme that metabolizes intracellular cAMP in T lymphocytes, neutrophils, and macrophages, and thereby inhibits inflammation (Rabe, 2011). It is approved for the treatment of severe COPD with frequent exacerbations (Rabe, 2011).

Bronchoconstriction of the airways is a hallmark of COPD, especially during exacerbations; patients suffer from a reduction in lung function (Rodriguez-Roisin, 2006; Rabe et al., 2007). Therefore, bronchodilators are currently standard

ABBREVIATIONS: ASM, airway smooth muscle; BAL, bronchoalveolar lavage; ChAT, choline acetyltransferase; COPD, chronic obstructive pulmonary disease; CS, cigarette smoke; H1N1, influenza A/PR/8/34, ICS, inhaled corticosteroid; IU, infectious unit; NANS, sialic acid synthase; PBS, phosphate-buffered saline; Penh, plethysmography measuring enhanced pause; PDE4, phosphodiesterase-4; qPCR, quantitative polymerase chain reaction; RSV, respiratory syncytial virus. 
therapeutics for COPD patients (Rabe et al., 2007). Treatment with the long-acting anticholinergic tiotropium bromide has been shown to have a positive effect on lung function, quality of life, and the frequency and severity of exacerbations (the UPLIFT and POET studies) (Tashkin et al., 2008; Vogelmeier et al., 2011). Tiotropium blocks M3 receptors on airway smooth muscle (ASM) cells and thereby prevents binding of acetylcholine and subsequent bronchoconstriction (Disse et al., 1999). Interestingly, recent studies suggest that tiotropium also has additional anti-inflammatory effects, possibly contributing to the efficacy seen in patients suffering from exacerbations (Arai et al., 2010; Cui, et al., 2010). For example, Wollin and Pieper (2010) found that tiotropium significantly reduced IL-6, TNF- $\alpha$, monocyte chemoattractant protein-1 (MCP-1), macrophage inflammatory protein-1 $\alpha$ (MIP-1 $\alpha$ ), and $\mathrm{KC}$ levels and neutrophil cell counts in bronchoalveolar lavage (BAL) fluid of cigarette smoke (CS)-exposed mice. Furthermore, tiotropium reduced inflammation and remodeling in several models of asthma (Gosens et al., 2005; Bos et al., 2007; Ohta et al., 2010; Buels et al., 2012; Bosnjak et al., 2014). In addition, several in vitro studies also attest to the anti-inflammatory properties of tiotropium (Buhling et al., 2007; Asano et al., 2008; Bateman, et al., 2009; Suzaki, et al., 2011).

The aim of this work was to investigate whether tiotropium has anti-inflammatory effects in mice in which inflammation is triggered by CS exposure and influenza virus (H1N1) or respiratory syncytial virus (RSV) infection. The effects were compared with those of fluticasone or roflumilast. Tiotropium exhibited anti-inflammatory effects that were often stronger than those of fluticasone or roflumilast.

\section{Materials and Methods}

Animals. We purchased 8- to 12-week-old female BALB/cAnNCrl mice from Charles River (Sulzfeld, Germany). They were housed in a specific pathogen-free facility at $20-25^{\circ} \mathrm{C}$ and received water and food ad libitum. All experimental procedures were performed in accordance with animal welfare regulations (Regierungspräsidium Tübingen, TVV 12-017).

Cigarette Smoke Exposure. Mice were exposed to CS of four cigarettes daily (Roth-Händle without filters; Badische Tabakmanufaktur Roth-Händle, Lahr, Germany) inside a perspex box for 10 days as described previously (Wollin and Pieper, 2010).

Infection. Mice were anesthetized with $3 \%$ isoflurane and infected 2 hours after CS exposure by administering $50 \mu \mathrm{l}$ of virus in phosphate-buffered saline (PBS) intranasally. Influenza A/PR/8/34 (H1N1) was provided by Boehringer Ingelheim (Laval, QC, Canada). Infection with 30 infectious units (IU) was performed 5 days before readout. RSV strain A-2 (obtained from Tebu-bio, Columbia, MD) infection and re-infection with $1 \times 10^{6}$ plaque-forming units was performed on the first day of the experiment and 1 day before readout.

Therapeutic Intervention. Mice were treated with tiotropium bromide, fluticasone propionate, or roflumilast 1 hour before CS exposure on each day of the experiment. Tiotropium bromide (Boehringer Ingelheim Pharma GmbH \& Co. KG, Biberach, Germany) was nebulized, and the animals were exposed in a perspex box for 5 minutes (Mundy and Kirkpatrick, 2004). Fluticasone propionate (Boehringer Ingelheim Pharma GmbH \& Co. KG) was micronized and dissolved in $1 \mathrm{ml}$ of PBS/0.04\% Tween 80, further diluted in PBS, and administered intranasally with the mice under isoflurane anesthesia (Crim et al., 2001). Roflumilast (Boehringer Ingelheim Pharma GmbH \& Co. KG) was micronized, dissolved in $1 \mathrm{ml}$ of PBS/0.02\% Tween 80 , and further diluted in $0.5 \%$ hydroxyethylcellulose (Hatzelmann and Schudt, 2001). Drug administration was performed by oral gavage.

Lung Function, Resistance, and Compliance. Lung function was measured on the last day of the experiment by noninvasive wholebody plethysmography measuring enhanced pause (Penh) values as described previously (Hamelmann et al., 1997). For resistance and compliance measurement, mice were anesthetized using a combination of $0.5 \mathrm{mg} / \mathrm{kg}$ metedomidin, $5 \mathrm{mg} / \mathrm{kg}$ midazolam, and $0.05 \mathrm{mg} / \mathrm{kg}$ fentanyl. Subsequently, the animals were intubated and connected to the Data Sciences International (St. Paul, MN) Buxco FinePointe Series Resistance and Compliance sites.

Measurement of Cell Counts in BAL Fluid. Four hours after the last CS exposure, mice were sacrificed by i.p. injection of an overdose pentobarbital (Merial GmbH, Hallbergmoos, Germany). Lungs were flushed twice with $0.8 \mathrm{ml}$ of lavage buffer (PBS containing $1 \%$ bovine serum albumin). Cell counts in BAL fluid were measured and differentiated using a Sysmex XT-1800i automated hematology analyzer.

Cytokine Measurement in Lung Homogenate. Lungs were removed and homogenized using a FastPrep-24 Sample Preparation System (MP Biomedicals, Irvine, CA). Cytokine levels in lung homogenate were assessed using Meso Scale Discovery multiplex technology (Meso Scale Discovery, Gaithersburg, MD) according to the manufacturer's instructions.

Detection of H1N1 and RSV. The amount of H1N1 in lung homogenate was determined using an immunofocus assay. MadinDarby canine kidney cells were seeded in 96 -well dishes at a density of $2 \times 10^{4}$ cells/well; $50 \mu \mathrm{l}$ of lung homogenate was incubated with the cells for 2 hours at $37^{\circ} \mathrm{C}$. Next, the wells were washed with PBS, and $200 \mu \mathrm{l}$ of Dulbecco's modified Eagle's medium containing 1\% fetal bovine serum and glutamine was added. After overnight incubation at $37^{\circ} \mathrm{C}$, cells were fixated using acetone/methanol and blocked for 1 hour with $2 \%$ normal goat serum in PBS. Biotinylated anti-H1N1 antibody NP MAB8258 (Millipore, Billerica, MA) was used for detection of infected cells. After the addition of streptavidin-peroxidase conjugate diluted 1:4000 in 2\% normal goat serum and true-blue substrate, stained cells were counted via light microscopy.

RSV in $50 \mu \mathrm{l}$ of lung homogenate was determined by quantitative polymerase chain reaction (qPCR). RNeasy Mini Kit (Qiagen, Hilden, Germany) was used for RNA isolation and purification according to the manufacturer's instructions. High-capacity cDNA reverse transcription kit (Applied Biosystems, Foster City, CA) was used to generate cDNA according to the manufacturer's instructions, and $2.5 \mu \mathrm{g}$ of total RNA was used for reverse transcription.

We performed qPCR using Taqman technology. A conserved region of the RSV N-gene was amplified. The following primers and probe were obtained from Sigma (Steinheim, Germany): forward, 5'-AGATCAACTTCTGTCATCCAGCAA-3'; reverse, 5' -TTCTGCACATCATAATTAGGAGTATCAAT-3'; probe, 5'-CACCATCCAACGGAGCACAGG AGAT- 3 '. The probe was labeled with the $5^{\prime}$ reporter dye 6-carboxyfluorescein and the $3^{\prime}$ quencher dye 6-carboxytetramethylrhodamin (TAMRA); $2 \mu \mathrm{l}$ of cDNA in a total volume of $10 \mu \mathrm{l}$ with QuantiFast Probe PCR Kit (Qiagen) was used for Taqman. Three technical replicates were generated. Additional reaction mixes containing $2 \mu \mathrm{l}$ of water instead of cDNA were used as no template control. Quantification was performed from standard curves of a pMA plasmid carrying a fragment of the RSV N-gene (provided by Life Technologies/GenArt). Results are expressed in fold change compared with the CS/RSV group.

qPCR Detection of Choline Acetyltransferase and Sialic Acid Synthase. To investigate changes in gene expression of choline acetyltransferase (ChAT) and sialic acid synthase (NANS) in lung homogenate, we used qPCR. RNA isolation and Taqman were performed as described for the detection of RSV. Ready-to-use ChAT and NANS gene expression assays were obtained from Thermo Fisher Scientific and used for the experiments. 18S rRNA was used as internal control. 
Histology. Histologic analysis of hematoxylin and eosin (H\&E)stained lung sections was performed as described (Duechs et al., 2014).

In Vitro Studies. On day 0, in 24-well format, 30,000 NCI-H292 cells/well were seeded. On day 1, tiotropium bromide, fluticasone propionate, or roflumilast was added. Drugs were dissolved in DMSO and further diluted in culture medium (RPMI1640 containing $5 \%$ fetal calf serum). Final drug concentrations were 10, 100, and $1000 \mathrm{nM}$. On day 4, culture medium was removed, and H1N1 or RSV diluted in $100 \mu$ l of PBS was added. Infection dose was $1 \times 10^{5} \mathrm{IU}$ for $\mathrm{H} 1 \mathrm{~N} 1$ and $1 \times 10^{6} \mathrm{PFU}$ for RSV. After incubation for 3 hours at $37^{\circ} \mathrm{C}$, the wells were washed with $200 \mu \mathrm{l}$ of PBS, and $600 \mu \mathrm{l}$ of medium containing the above-mentioned treatments was added. On day 7, the medium was removed, and $200 \mu \mathrm{l}$ of buffer RLT containing $1 \%$ $\beta$-mercaptoethanol was added to each well. RNA was isolated from cell lysate (Qiagen) and a high-capacity cDNA reverse transcription kit (Applied Biosystems) was used for the generation of cDNA according to the manufacturer's instructions; $2.5 \mu \mathrm{g}$ of total RNA was used for reverse transcription. We performed qPCR using Taqman technology. For RSV, the same primers were used as already described. For H1N1, the following primers and probe were obtained from Sigma (Steinheim, Germany): forward 1, 5'-GGACTGCAGCGTAGACGCTT-3'; forward 2, 5'-CATCCTGTTGTATATGAGGCCCAT-3'; reverse, 5'-CATTCTGTTGTATATGAGGCCC; AT-3'; probe, 5'-CTCAGTTATTCTGCTGGTGCACTTGCCA-3'. The probe was labeled with the $5^{\prime}$ reporter dye 6-carboxyfluorescein and the $3^{\prime}$ quencher dye 6-carboxytetramethylrhodamin (TAMRA). $2 \mu \mathrm{l}$ of cDNA in a total volume of $10 \mu \mathrm{l}$ with QuantiFast Probe PCR Kit (Qiagen) was used for Taqman. Three technical replicates were generated. Additional reaction mixes containing $2 \mu \mathrm{l}$ of water instead of cDNA were used as no template control. The $\Delta \Delta \mathrm{C}_{\mathrm{t}}$-method after qPCR was used for the investigation of relative changes in in H1N1 amount in samples. Results are expressed in fold change compared with infected cells without treatment.

Software and Statistical Analysis. Microsoft Office 2010 and GraphPad Prism 6.01 (GraphPad Software, San Diego, CA) were used for data analysis and presentation. Multiple comparisons were performed by one-way analysis of variance with Dunnett's post-test. Nonparametric Kruskal-Wallis test was used upon unequal variances. For comparison of two groups, unpaired $t$ test was used. Data are expressed as mean \pm S.E.M. $* * * * P<0.0001$, $* * * P<0.001$, $* * P<$ 0.01 , and $* P<0.05$ represent significant differences compared with controls.

\section{Results}

H1N1 Exacerbates Pulmonary Inflammation in CSExposed Mice. To develop a model which reflects aspects of COPD exacerbation, mice were exposed to CS and infected with different dosages of H1N1 (see Supplemental Fig. E1). Figure 1A illustrates a protocol using 30 IU H1N1 for infection, which depicts best the relevant aspects of an exacerbation. Whereas CS exposure or H1N1 infection resulted in a low or moderate loss of body weight, combination of the stimuli led to a significant loss of body weight (Fig. 1B). As shown in Fig. 1C, neither CS exposure nor H1N1 infection alone resulted in significantly increased Penh values. In contrast, lung function was significantly impaired upon CS exposure and additional H1N1 infection. Measured Penh value was $1.65 \pm 0.18$ compared with $0.40 \pm 0.014$ of the control animals. Whereas CS exposure alone did not significantly increase cytokine levels in lung homogenate, H1N1 infection of the animals resulted in significantly increased levels of IL-6, KC, TNF- $\alpha$, IL- $1 \beta$, and IFN- $\gamma$ (Fig. 1D); however, H1N-induced cytokine influx was lower in comparison with animals receiving CS and H1N1. In CS-exposed and H1N1-infected animals IL-6, KC, TNF- $\alpha$, IL- $1 \beta$, and IFN- $\gamma$ were significantly elevated. Furthermore, quantification of H1N1 load in lung homogenate revealed that the amount of virus was highest in mice exposed to CS before infection with the virus (Fig. 1F). Infection of mice with H1N1 significantly increased the accumulation of total cells, neutrophils, and macrophages in BAL fluid (Fig. 1E). Surprisingly, additional CS exposure of $\mathrm{H} 1 \mathrm{~N}$-infected mice did not further increase cellular influx into the lungs.

Tiotropium Shows Anti-inflammatory Effects in CS-Exposed and H1N1-Infected Mice. To investigate whether tiotropium showed anti-inflammatory effects in CS/ H1N1-exposed mice, the animals were treated with the drug for a total of 10 days (Fig. 2A). Treatment with tiotropium did not influence body weight (Fig. 2B). At a concentration of $0.3 \mathrm{mg} / \mathrm{ml}$, tiotropium decreased Penh values and airway resistance significantly, indicating improved lung function (Fig. 2C). Cytokine levels of IL-6 and IFN- $\gamma$ were reduced in lung homogenate of animals treated with tiotropium (Fig. 2D). In addition, tiotropium significantly reduced total cells, neutrophils, and macrophages in BAL fluid (Fig. 2E).

Treatment with Fluticasone Increases the Loss of Body Weight, Worsens Lung Function, and Fails to Reduce Pulmonary inflammation. Next, the effect of the corticosteroid fluticasone was investigated in this model. The protocol shown in Fig. 3A illustrates the experimental scheme. On treatment with $0.3 \mathrm{mg} / \mathrm{kg}$ or $0.5 \mathrm{mg} / \mathrm{kg}$, an aggravated loss of body weight was observed in comparison with CS-exposed and H1N1-infected mice without treatment (Fig. 3B). Furthermore, Penh values increased significantly in a dose-dependent manner upon fluticasone treatment, and compliance values were lowered significantly (Fig. 3C). Whereas the Penh value was $1.86 \pm 0.21$ for the CS-exposed and additionally H1N1-infected mice, it peaked at a value of $6.30 \pm 0.94$ in mice treated with $0.5 \mathrm{mg} / \mathrm{kg}$ of the corticosteroid. In contrast to its described anti-inflammatory effect (van der Velden, 1998), treatment with fluticasone failed to reduce cytokines in lung homogenate or cell counts in BAL fluid in the CS-exposed and H1N1-infected mice. As illustrated in Fig. 3D, drug administration moreover significantly increased levels of IL-6, KC, and TNF- $\alpha$.

These results were surprising, and we investigated whether this is a fluticasone-specific or a general corticosteroid effect. For this purpose, we tested the effects of dexamethasone in this model. Supplemental Fig. E2 shows that dexamethasone also increased weight loss and had no positive effect on airway resistance and compliance or neutrophil numbers in the CS/ H1N1-exposed mice. However, in contrast to fluticasone, dexamethasone treatment reduced the levels of KC, IL- 6 , IL- $\beta$, and IFN- $\gamma$ in these animals.

Roflumilast Decreases Levels of Cytokines and Cell Counts but Does not Improve Lung Function. The effect of the PDE4 inhibitor roflumilast treatment in the CS/H1N1 combination model was investigated. As shown in Fig. 4, D and $\mathrm{E}$, both cytokines and cell counts decreased with treatment. Levels of IL-6, KC, and IFN- $\gamma$ were significantly lower in lung homogenate, and total cells and macrophages decreased significantly in BAL fluid at a dosage of $1.0 \mathrm{mg} / \mathrm{kg}$. Drug administration had no effect on the loss of body weight (Fig. 4B). Moreover, it had no effect on Penh values or lung resistance and compliance (Fig. 4C). 
A

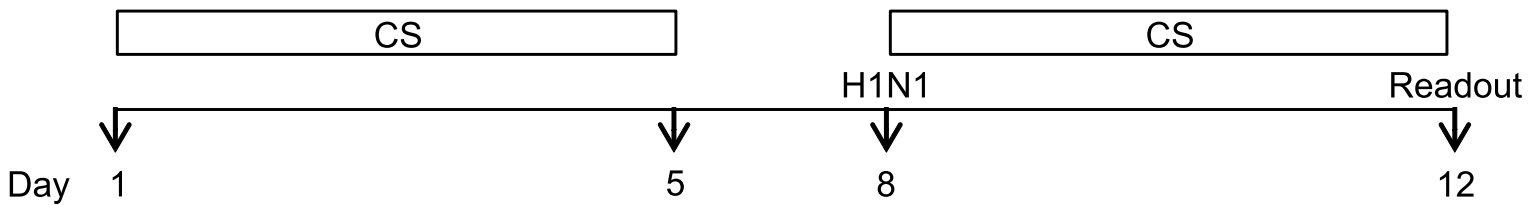

B

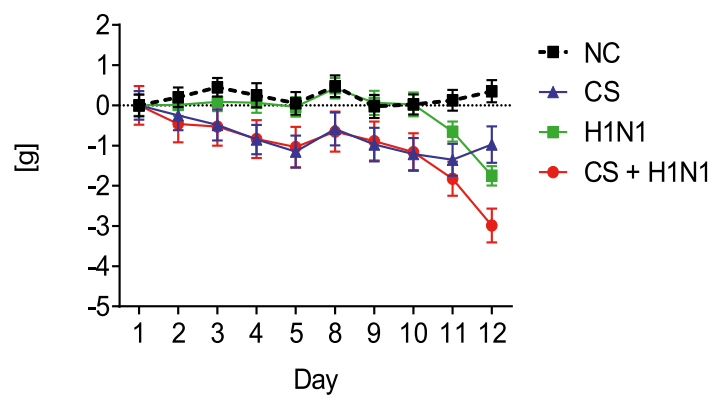

D

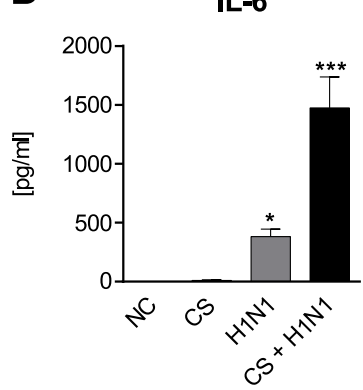

IL-1 $\beta$

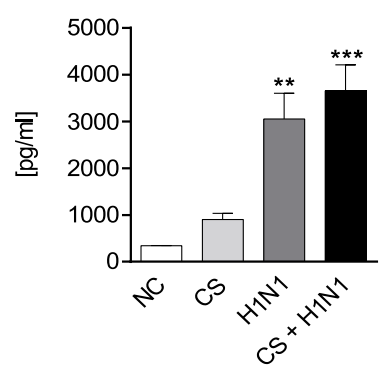

F

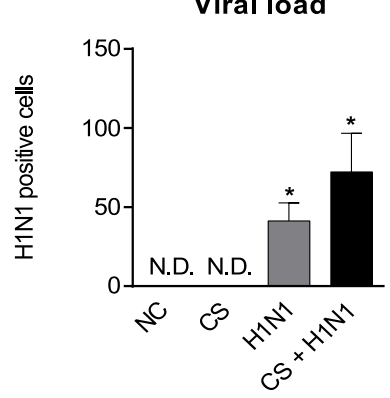

KC

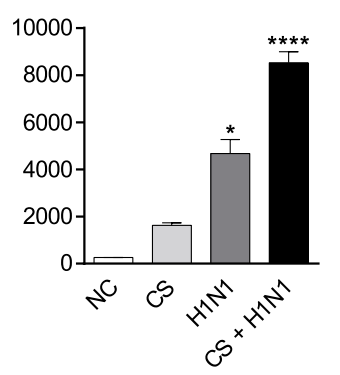

IFN- $\gamma$

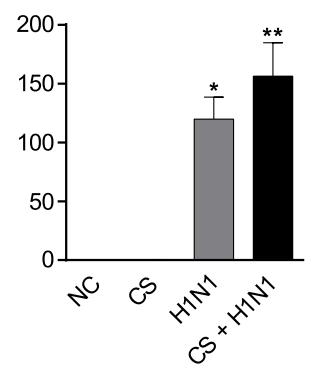

C

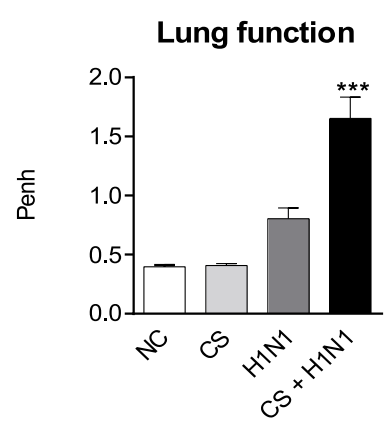

TNF-a

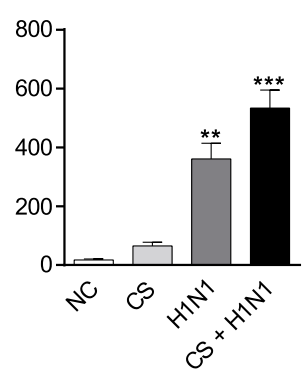

E

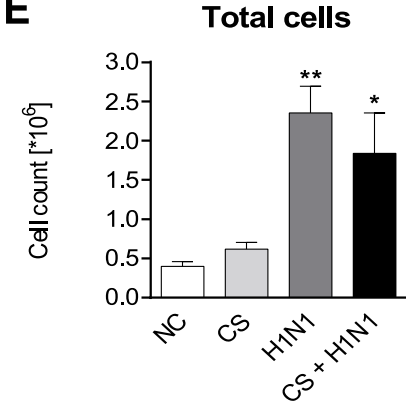

Neutrophils

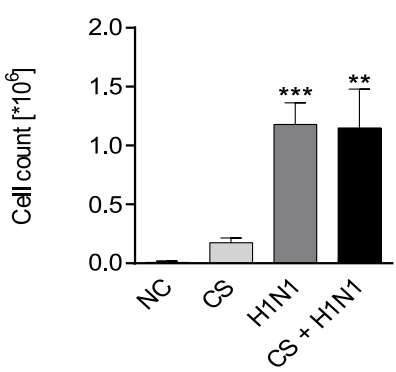

Macrophages

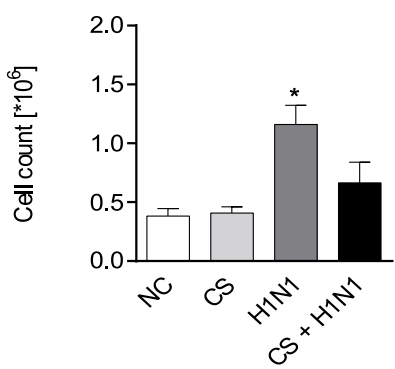

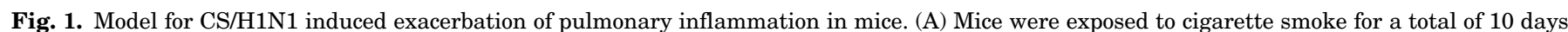

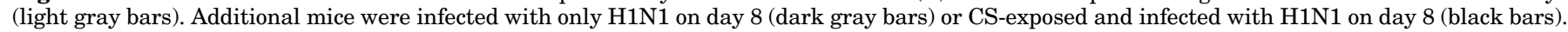

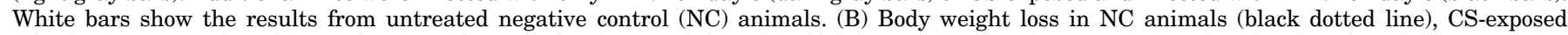

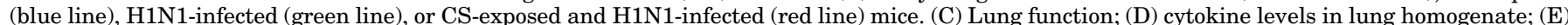

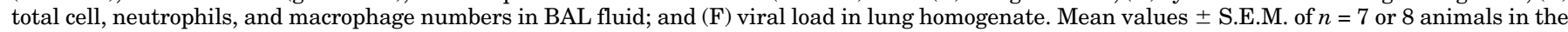

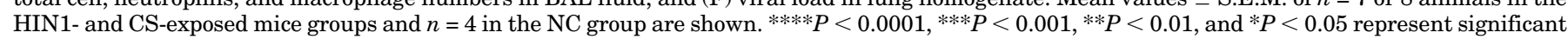
differences compared with the NC group. 
A

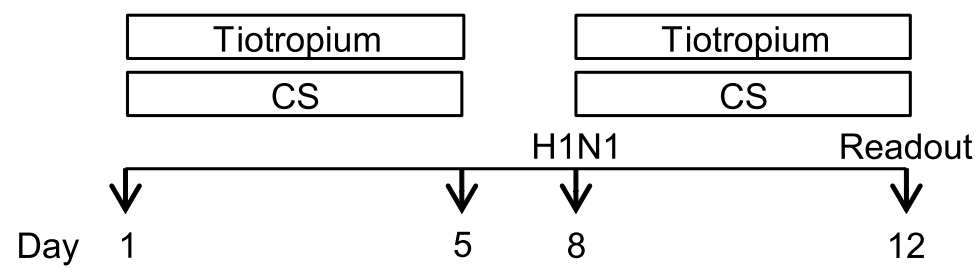

B

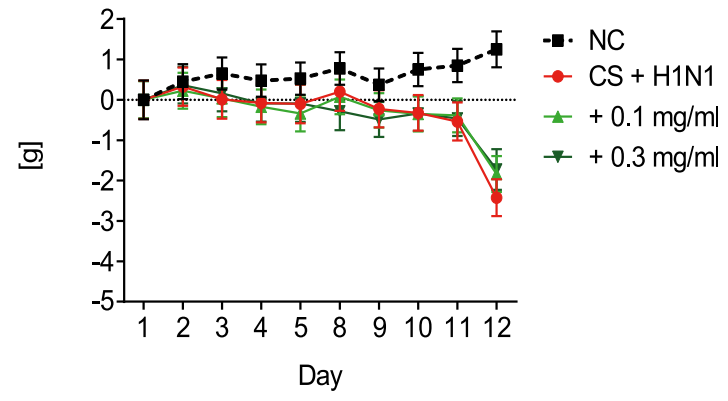

C

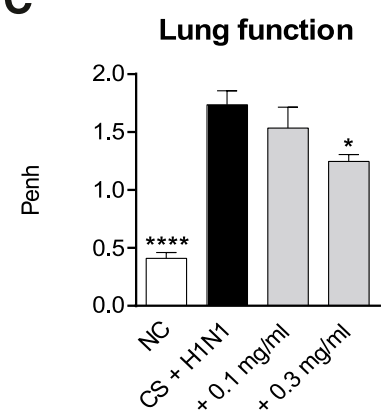

D

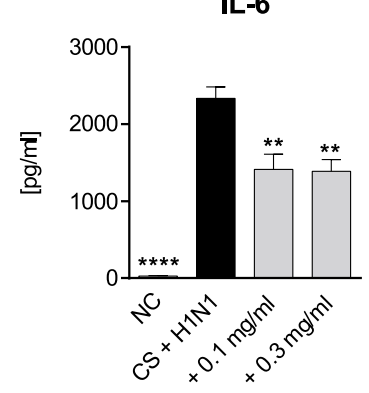

IL-1 $\beta$

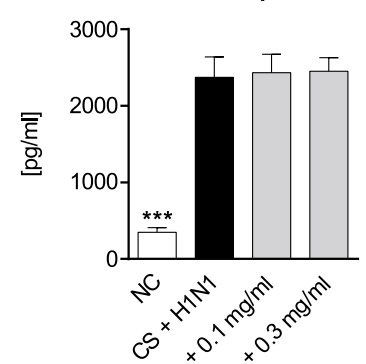

Compliance

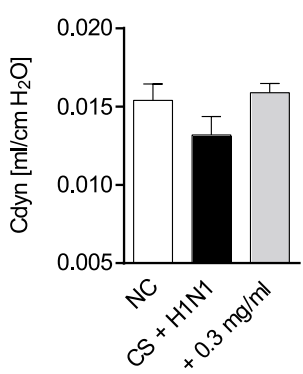

KC

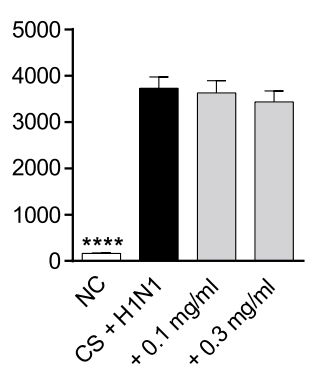

IFN- $\gamma$

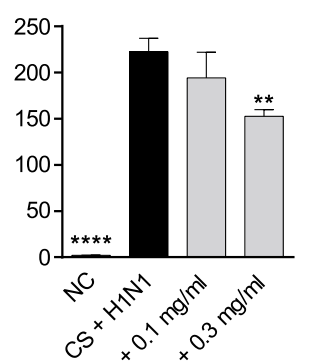

E

Resistance

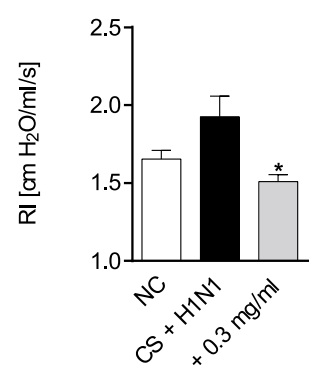

TNF- $a$

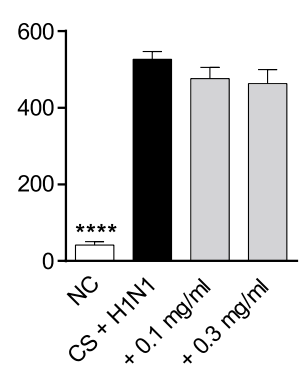

Total cells
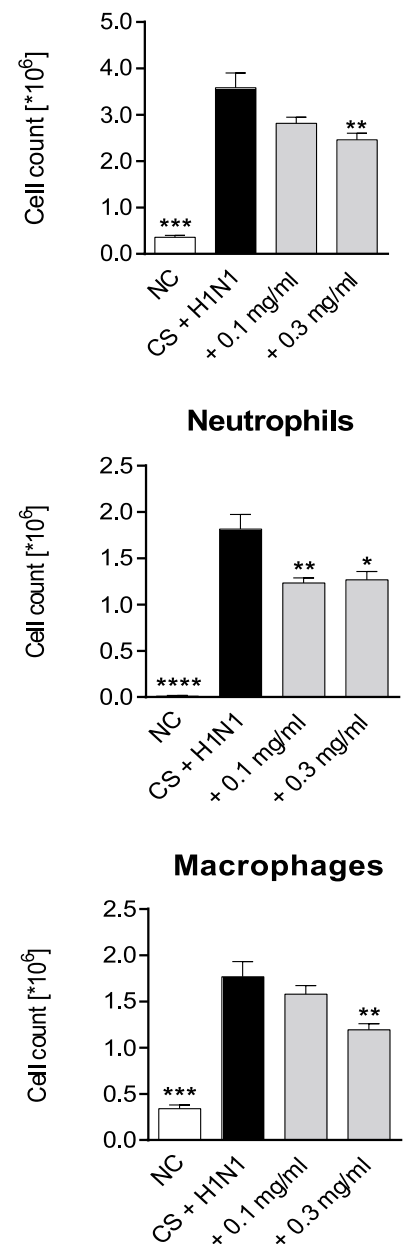

Fig. 2. Tiotropium treatment of CS-exposed and H1N1-infected mice. (A) CS-exposed and H1N1-infected mice (black bars) were treated for a total of 10 days with $0.1 \mathrm{mg} / \mathrm{ml}$ or $0.3 \mathrm{mg} / \mathrm{ml}$ nebulized tiotropium (gray bars). White bars show the results from untreated negative control (NC) animals. (B) Body weight loss in NC mice (black dotted line), untreated CS-exposed, and H1N1-infected mice (red line); CS-exposed and H1N1-infected mice treated with $0.1 \mathrm{mg} / \mathrm{ml}$ (light green line); or $0.3 \mathrm{mg} / \mathrm{ml}$ (dark green line) nebulized tiotropium. (C) Lung function, resistance, compliance, and (D) cytokine levels in lung homogenate and (E) total cell, neutrophil, and macrophage numbers in BAL fluid. Mean values \pm S.E.M. of $n=7$ or 8 animals in the HIN1- and CSexposed mice groups and $n=4$ in the NC group. ${ }^{* * * *} P<0.0001$, $* * * P<0.001$, $* * P<0.01$, and $* P<0.05$ represent significant differences compared with CS-exposed and H1N-infected group.

Fluticasone Treatment Increases the Amount of H1N1 In Vivo and In Vitro. We determined the amount of $\mathrm{H} 1 \mathrm{~N} 1$ in the lungs of CS-exposed mice and investigated the effects of treatment with tiotropium, fluticasone, and roflumilast. In addition, we tested the effect of the mentioned treatments in human bronchial epithelial cell culture. Figure 5A shows that treatment with tiotropium and roflumilast did not increase the amount of virus present in the lungs compared with the control group. In contrast, the amount of H1N1 increased significantly in the lungs of the fluticasone-treated mice versus the controls. Consistent with these findings, the viral load also increased significantly in vitro upon treatment of H1N1-infected cells with fluticasone but not treatment with tiotropium or roflumilast (Fig. 5B). We 
A

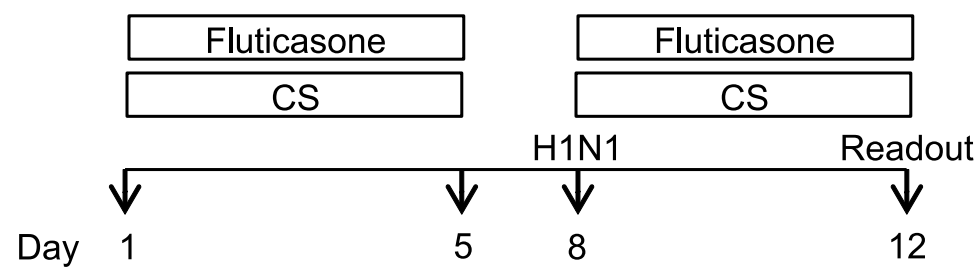

C

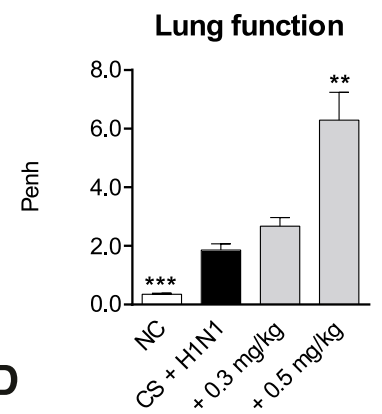

IL-6

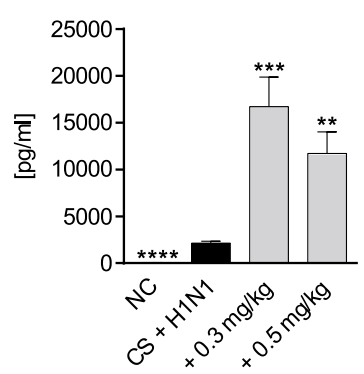

IL-1 $\beta$
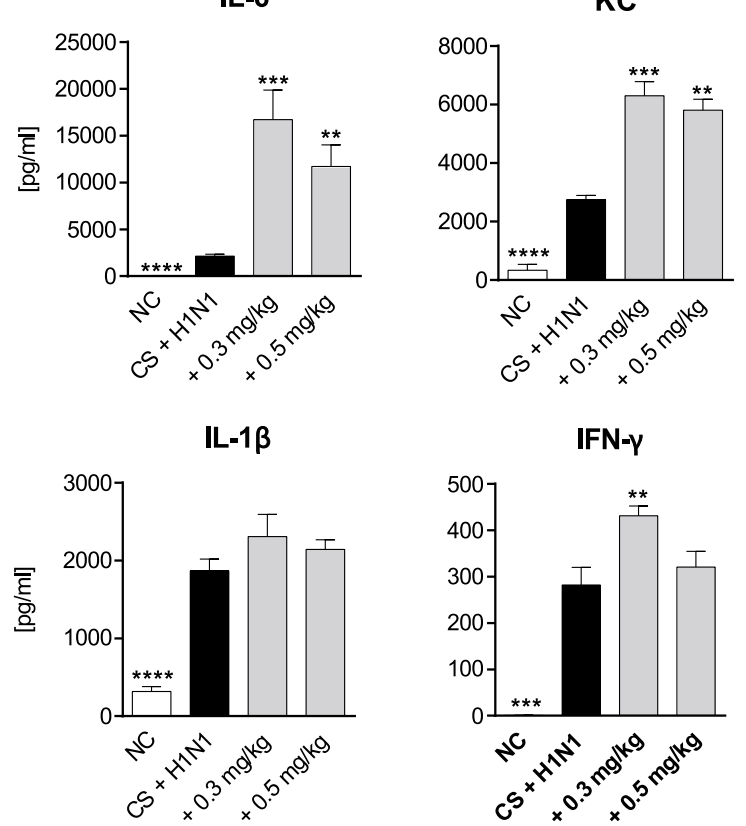

IFN- $\gamma$

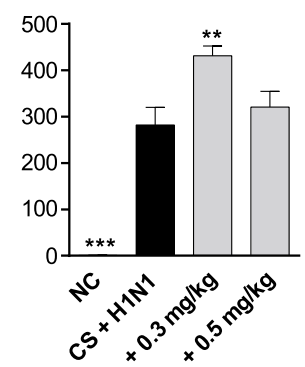

B

Body-weight

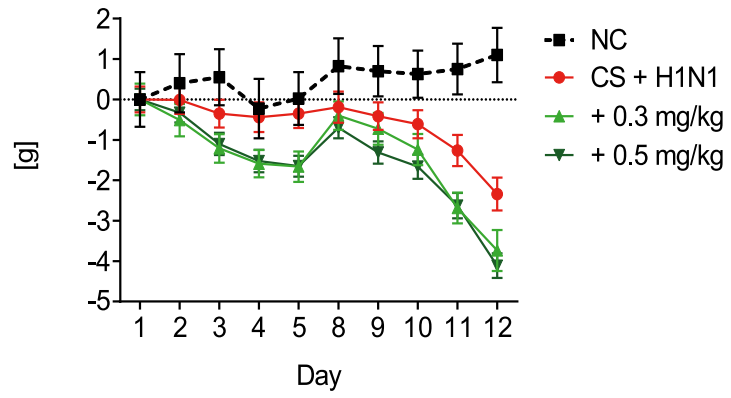

E

Resistance

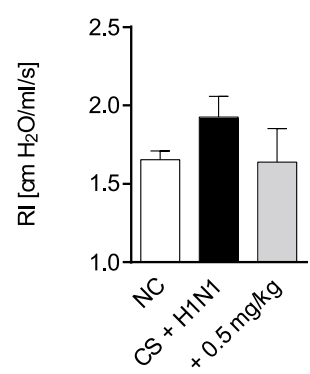

TNF-a

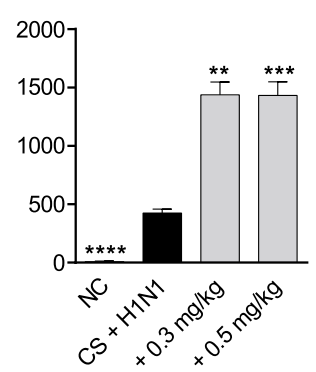

Total cells

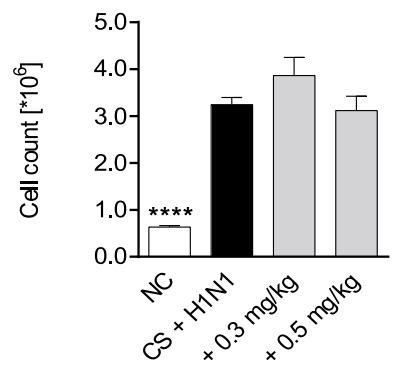

Neutrophils
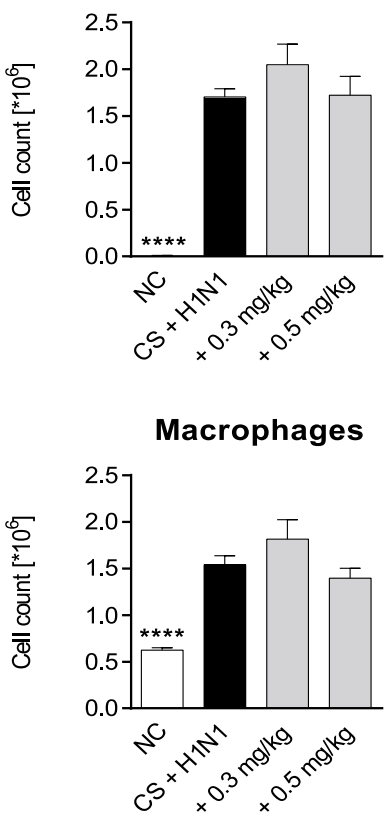

Fig. 3. Fluticasone treatment of CS-exposed and H1N1-infected mice. (A) CS-exposed and H1N1- infected mice (black bars) were treated with 0.3 mg/kg or $0.5 \mathrm{mg} / \mathrm{kg}$ fluticasone (gray bars). White bars show the results from untreated negative control (NC) animals. (B) Body weight loss in NC mice (black dotted line), untreated CS-exposed, and H1N1-infected mice (red line); CS-exposed and H1N1-infected mice treated with $0.3 \mathrm{mg} / \mathrm{kg}$ (light green line) or $0.5 \mathrm{mg} / \mathrm{kg}$ (dark green line) fluticasone. (C) Lung function, resistance, compliance; (D) cytokine levels in lung homogenate; (E) total cell, neutrophil, and macrophage numbers in BAL fluid. Mean values \pm S.E.M. of $n=4-8$ animals in the HIN1- and CS-exposed mice groups and $n=4$ in the NC group. $* * * * P<0.0001,{ }^{* * *} P<0.001,{ }^{*} P<0.01$, and $* P<0.05$ represent significant differences compared with CS-exposed and H1N1-infected group.

also found that dexamethasone increased viral load in the CS/ H1N1-treated mice (Supplemental Fig. E2) and NCI-H292 cells in vitro (data not shown).

Histologic Examination of the Lungs of the CS/H1N1Exposed Mice Treated with the Different Drugs. Figure 5C shows H\&E-stained lung sections of the negative control and CS/ H1N1-exposed animals that were additionally treated with tiotropium, fluticasone, or roflumilast. Negative control mice showed normal lung morphology. Lungs of mice that were exposed to $\mathrm{CS}$ and infected with $\mathrm{H} 1 \mathrm{~N} 1$ exhibited peribronchial disseminated inflammation. Upon treatment with $0.5 \mathrm{mg} / \mathrm{kg}$ fluticasone, loss of epithelial cells in the main bronchus increased. In contrast, the integrity of epithelia of the main bronchi in lungs of mice treated with $0.3 \mathrm{mg} / \mathrm{ml}$ tiotropium was less affected. No changes were detectable in the lungs of mice treated with $1.0 \mathrm{mg} / \mathrm{kg}$ roflumilast compared with the lungs of mice of the $\mathrm{CS} / \mathrm{H} 1 \mathrm{~N} 1$ group. 
A

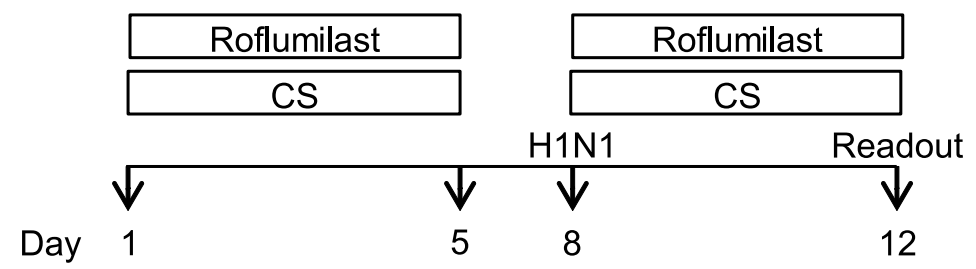

B

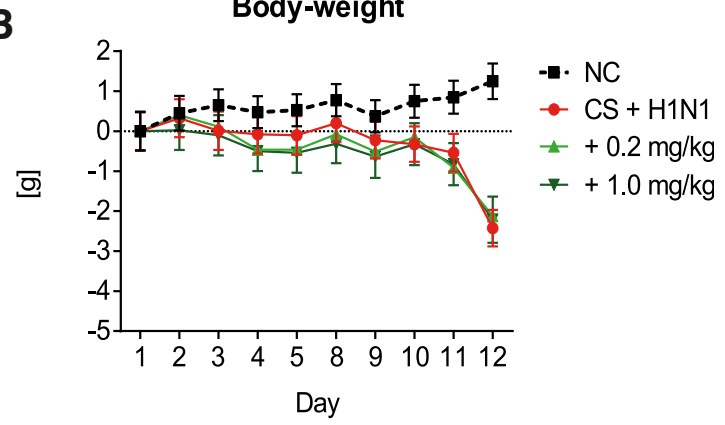

C

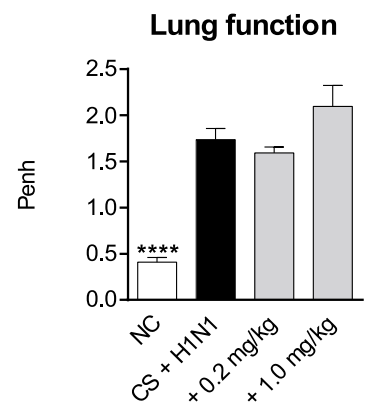

IL-6

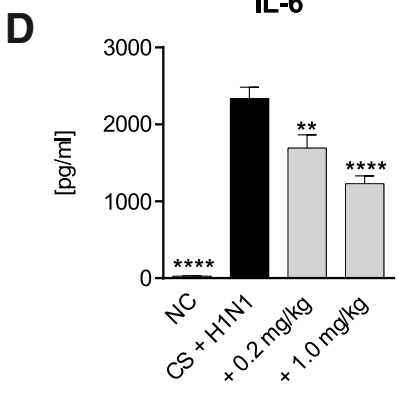

IL-1 $\beta$

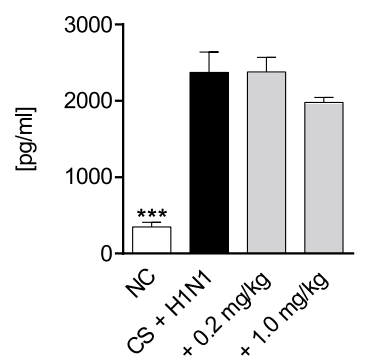

Compliance

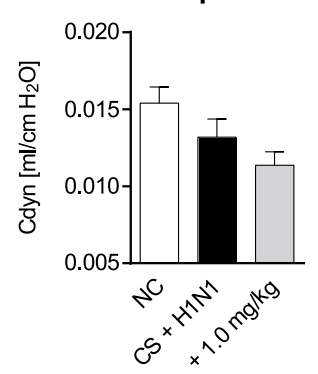

KC

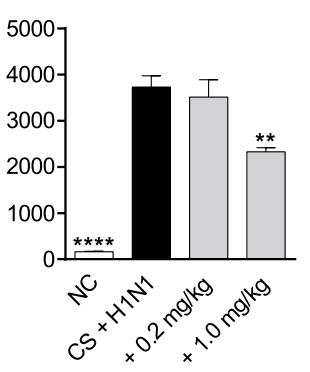

IFN- $\gamma$

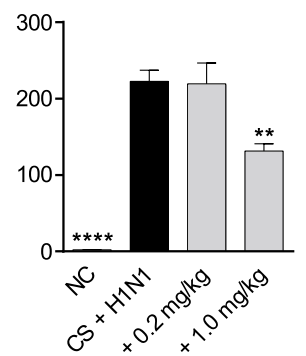

Resistance

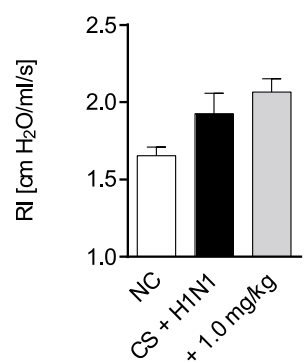

TNF- $a$

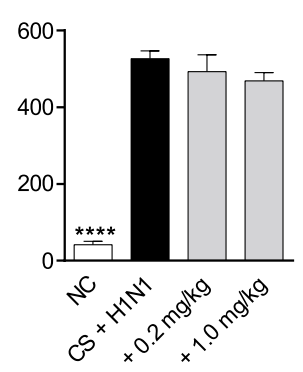

E
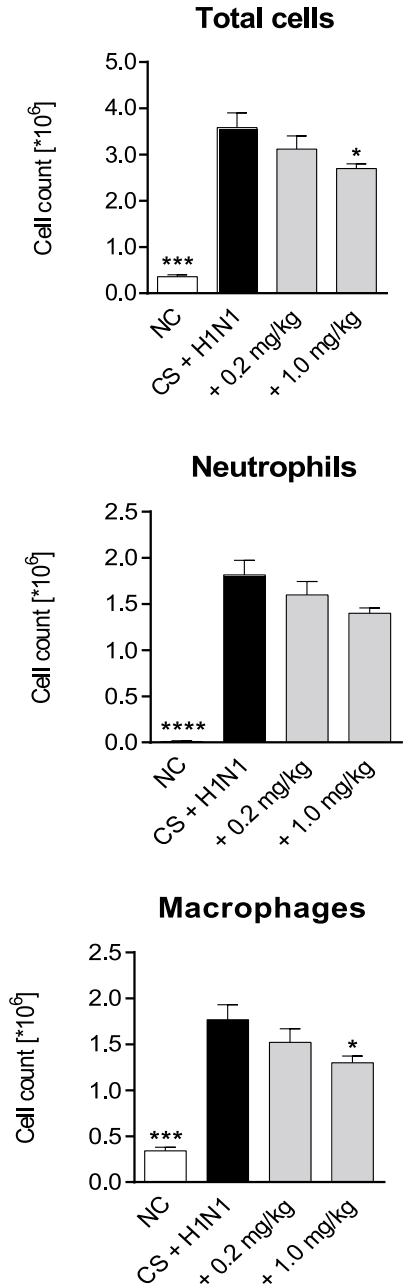

Fig. 4. Roflumilast treatment of CS-exposed and H1N1-infected mice. (A) CS-exposed and H1N1-infected mice (black bars) were treated with 0.2 mg/kg or $1.0 \mathrm{mg} / \mathrm{kg}$ roflumilast (gray bars). White bars show the results from untreated negative control (NC) animals. (B) Body weight loss in NC mice (black dotted line), untreated CS-exposed and H1N1-infected mice (red line), CS-exposed and H1N1-infected mice treated with $0.2 \mathrm{mg} / \mathrm{kg}$ (light green line), or $1.0 \mathrm{mg} / \mathrm{kg}$ (dark green line) roflumilast. (C) Lung function, resistance, compliance and (D) cytokine levels in lung homogenate (E) total cell, neutrophil, and macrophage numbers in BAL fluid. Mean values \pm S.E.M. of $n=7$ or 8 animals in the HIN1- and CS-exposed mice groups and $n=4$ in the NC group. $* * * * P<0.0001,{ }^{*} * * P<0.001, * * P<0.01$, and $* P<0.05$ represent significant differences compared with the CS-exposed and H1N1-infected group.

Tiotropium but not Fluticasone or Roflumilast has Anti-inflammatory Effects in a CS/RSV Re-infection Model. We also investigated the anti-inflammatory effects of tiotropium in a CS/RSV combination model. For this purpose, we exposed mice to $\mathrm{CS}$ and used a re-infection protocol for the administration of the virus (Fig. 6A). Treatment with roflumilast, and in particular fluticasone, increased the loss of body weight in the CS/RSV combination model, whereas tiotropium did not (Fig. 6B). Treatment with tiotropium, but not fluticasone or roflumilast, reduced the neutrophil cell count in BAL fluid significantly (Fig. 6C). None of the drugs reduced macrophage numbers (data not shown). Table 1 shows cytokine levels in lung homogenate of CS/RSV-exposed and drugtreated mice. Tiotropium reduced levels of IL- 6 , IFN- $\gamma$, TNF- $\alpha$, and KC, being significant for IL- 6 , IFN- $\gamma$, and TNF- $\alpha$. Treatment with fluticasone decreased IFN- $\gamma$ levels but increased the 
A

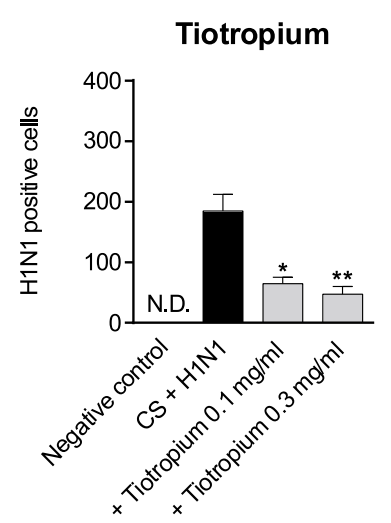

C
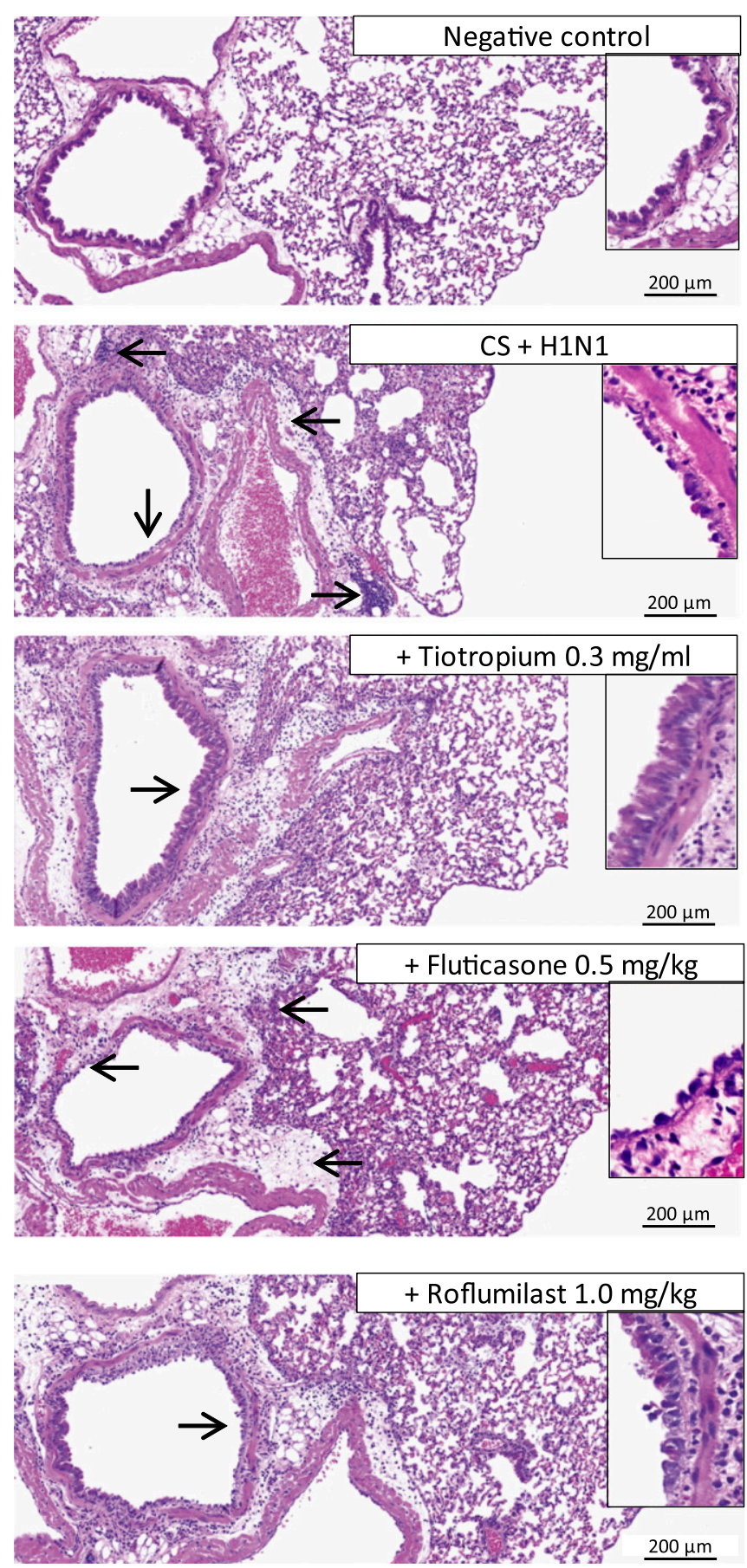

Fig. 5. H1N1 virus load and histologic changes of the lung in H1N1-infected and CS-exposed mice after treatment with tiotropium, fluticasone, or roflumilast. (A) Mice were exposed to CS and infected with $\mathrm{H} 1 \mathrm{~N} 1$ and additionally treated with either tiotropium $(0.1 \mathrm{mg} / \mathrm{ml}$ or $0.3 \mathrm{mg} / \mathrm{ml})$, fluticasone $(0.3 \mathrm{mg} / \mathrm{kg}$ or $0.5 \mathrm{mg} / \mathrm{kg})$, or roflumilast $(0.2 \mathrm{mg} / \mathrm{kg}$ or $1.0 \mathrm{mg} / \mathrm{kg})$. Shown is the mean $+/-\mathrm{SEM}$ viral load in lung homogenate of $n=7$ or 8 mice per group measured by immunofocus assay. (B) NCI-H292 cells were infected with H1N1 and treated with tiotropium, fluticasone, or roflumilast as described in Materials and Methods. Changes in virus load were measured in cell lysates using qPCR (mean \pm S.E.M. of $n=4$ separate wells per group). (C) H\&E stains of lung sections from untreated negative control (NC) mice, mice exposed to CS and H1N1, or CS/H1N1-exposed/infected mice, which were additionally treated with tiotropium, fluticasone, or roflumilast. Arrows indicate areas of inflammation or structural changes. Lungs of $n=6-8$ mice per group were analyzed and representative sections shown. $* * * * P<0.0001, * * * P<$ $0.001, * * P<0.01$, and $* P<0.05$ represent significant differences compared with the CS-exposed and H1N1-infected group or the H1N1infected cells.

amount of KC. Roflumilast increased the level of $\mathrm{KC}$ without having any effects on the other measured cytokines.

Fluticasone Treatment Increases the Amount of RSV In Vivo and In Vitro. Consistent with previous findings for
$\mathrm{H} 1 \mathrm{~N} 1$, treatment with fluticasone increased the amount of virus in the airways of CS-exposed and RSV-infected mice compared with controls (Fig. 7A). RSV load in human bronchial epithelial cell culture was also significantly elevated 
A

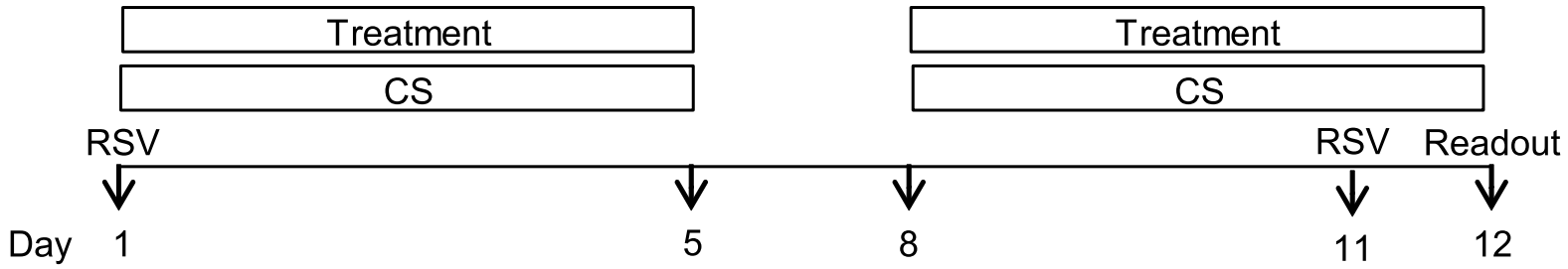

B

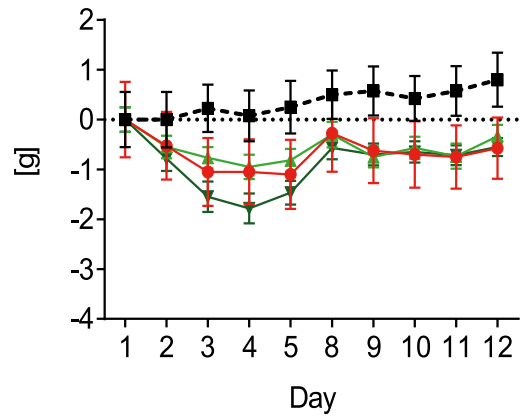

-m. Negative control

- CS + RSV

- + Tiotropium $0.1 \mathrm{mg} / \mathrm{ml}$

$\rightarrow+$ Tiotropium $0.3 \mathrm{mg} / \mathrm{ml}$

C

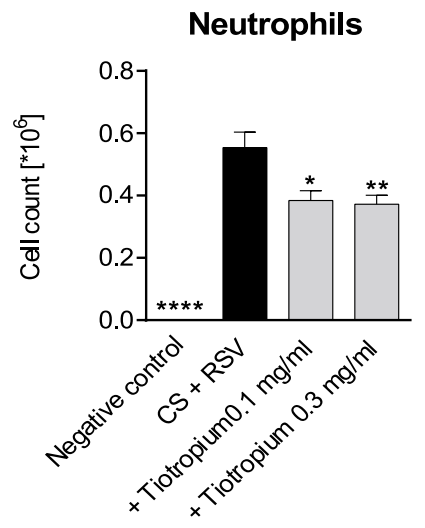

Fluticasone

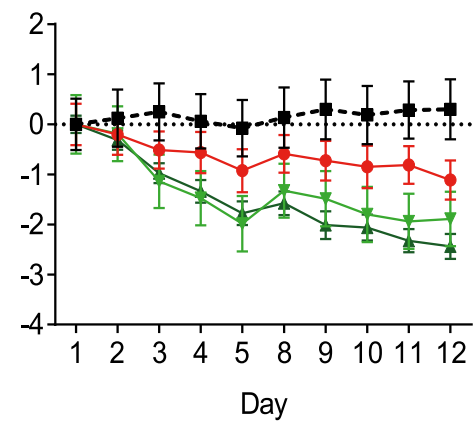

-๘. Negative control

- CS + RSV

$\rightarrow+$ Fluticasone $0.1 \mathrm{mg} / \mathrm{kg}$

$\star$ + Fluticasone $0.3 \mathrm{mg} / \mathrm{kg}$

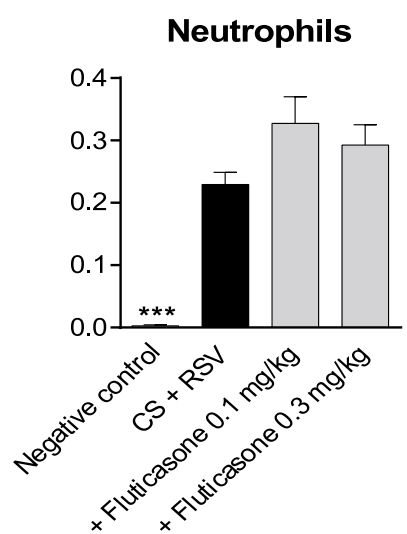

Roflumilast

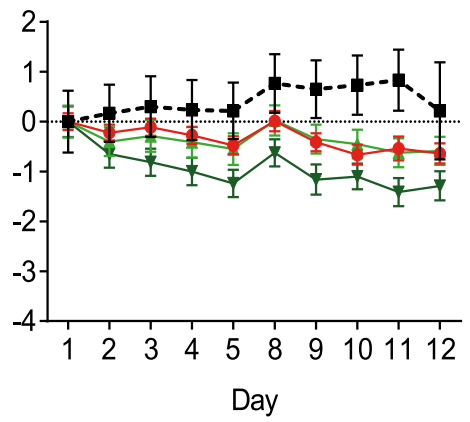

- Negative control

$\bullet$ CS + RSV

$\star+$ Roflumilast $0.2 \mathrm{mg} / \mathrm{kg}$

$\rightarrow+$ Roflumilast $1.0 \mathrm{mg} / \mathrm{kg}$

Neutrophils

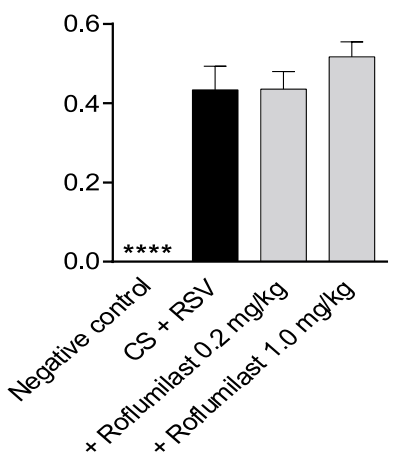

Fig. 6. Tiotropium, fluticasone, and roflumilast treatment in a CS/RSV re-infection model. (A) Mice were exposed to CS and infected with RSV on day 1 and re-infected with the virus on day 11 . CS- and RSV-exposed mice were treated with tiotropium $(0.1 \mathrm{mg} / \mathrm{ml} \mathrm{or} 0.3 \mathrm{mg} / \mathrm{ml})$, fluticasone $(0.1 \mathrm{mg} / \mathrm{kg}$ or $0.3 \mathrm{mg} / \mathrm{kg}$ ), or roflumilast $(0.2 \mathrm{mg} / \mathrm{kg}$ or $1.0 \mathrm{mg} / \mathrm{kg}$ ). (B) Development of body weight over time and (C) neutrophil numbers in the BAL fluid were investigated. Mean values \pm S.E.M. of $n=4-8$ animals per group are shown. $* * * * P<0.0001, * * * P<0.001$, $* * P<0.01$, and $* P<0.05$ represent significant differences compared with the CS-exposed and RSV-infected group.

upon treatment with fluticasone. In contrast, tiotropium and roflumilast treatment had no effect on the amount of RSV load in the CS/RSV-exposed mice (Fig. 7A) and NCI-H292 cell culture (Fig. 7B).

Tiotropium Downregulates ChAT and NANS Expression in CS/H1N1-Exposed Mice. We investigated the effect of dexamethasone, fluticasone, roflumilast, and tiotropium on gene expression of ChAT and NANS. We found the expression of both genes significantly upregulated in mice challenged with CS and H1N1 (Fig. 8). Dexamethasone, fluticasone, or roflumilast treatment had no effect on ChAT or NANS expression. By contrast, a strong and significant downregulation of ChAT and NANS expression was observed in lung homogenate of tiotropiumtreated mice.

\section{Discussion}

Patients who have COPD suffer from bronchoconstriction, which contributes to a reduction in lung function, especially during episodes of viral-induced exacerbations (RodriguezRoisin, 2006; Rabe et al., 2007). Treatment with tiotropium was shown to improve lung function, quality of life and to reduce the frequency and severity of exacerbations in COPD patients. It is currently a standard treatment of COPD (Keam and Keating, 2004; Tashkin et al., 2008; Mamary and Criner, 2009; Magnussen et al., 2014). Tiotropium blocks M3 muscarinic receptors on ASM cells, thereby preventing bronchoconstriction explaining the positive effects on lung function and quality of life observed in patients (Disse et al., 1999). How tiotropium reduces the 
TABLE 1

Cytokine levels in the lungs of cigarette smoke (CS)/respiratory syncytial virus (RSV)-exposed mice after treatment with tiotropium (Tio), fluticasone (Fluti), and roflumilast (Roflu)

Mice were exposed to CS, infected and re-infected with RSV, and treated with tiotropium, fluticasone, or roflumilast as described in Fig. 6 and Materials and Methods. Cytokine levels in lung homogenate were analyzed using Meso Scale Discovery multiplex technology. Mean \pm S.E.M. of $n=4-8$ animals per treatment group and $n=4$ for negative control is shown.

\begin{tabular}{lcccc}
\hline Mediator $[\mathrm{pg} / \mathrm{ml}]$ & Negative Control & Smoke $+\mathrm{RSV}$ & + Tio $0.1 \mathrm{mg} / \mathrm{ml}$ & + Tio $0.3 \mathrm{mg} / \mathrm{ml}$ \\
\hline IL-6 & $20.4 \pm 3.1^{* *}$ & $173.9 \pm 35.9$ & $128.2 \pm 20.9$ & $87.5 \pm 10.7^{*}$ \\
KC & $99.9 \pm 28.0^{* * *}$ & $673.6 \pm 61.5$ & $523.0 \pm 72.4$ & $499.0 \pm 37.9$ \\
TNF- $\alpha$ & $0.9 \pm 0.4^{* * *}$ & $37.1 \pm 5.1$ & $21.5 \pm 1.8^{* *}$ & $25.0 \pm 2.4^{*}$ \\
IL-1 $\beta$ & $60.5 \pm 13.0^{* *}$ & $500.4 \pm 92.9$ & $578.0 \pm 52.0$ & $575.5 \pm 44.5$ \\
IFN- $\gamma$ & $<3.1$ & $336.1 \pm 46.4$ & $169.2 \pm 28.8 *$ & $182.6 \pm 34.3 *$ \\
& & & \\
IL-6 & Negative control & Smoke $+\mathrm{RSV}$ & + Fluti $0.1 \mathrm{mg} / \mathrm{kg}$ & + Fluti $0.3 \mathrm{mg} / \mathrm{kg}$ \\
KC & $<25.5$ & $47.7 \pm 9.8$ & $88.8 \pm 21.1$ & $122.4 \pm 55.0$ \\
TNF- $\alpha$ & $154.0 \pm 19.2^{* * * *}$ & $720.6 \pm 39.9$ & $1932.1 \pm 134.3^{* * *}$ & $1462.0 \pm 169.2^{*}$ \\
IL-1 $\beta$ & $4.0 \pm 1.1 * * *$ & $24.7 \pm 1.4$ & $27.0 \pm 2.1$ & $22.9 \pm 2.1$ \\
IFN- $\gamma$ & $51.4 \pm 10.8 * * * *$ & $532.4 \pm 40.7$ & $1184.6 \pm 169.3^{* * *}$ & $811.9 \pm 94.7$ \\
& $0.3 \pm 0.1^{* * *}$ & $81.8 \pm 10.0$ & $53.4 \pm 6.9 *$ & $39.2 \pm 5.7 * *$ \\
IL-6 & & & \\
KC & Negative control & Smoke $+\mathrm{RSV}$ & $+\mathrm{Roflu} 0.2 \mathrm{mg} / \mathrm{kg}$ & $+\mathrm{Roflu} 1.0 \mathrm{mg} / \mathrm{kg}$ \\
TNF- $\alpha$ & $10.5 \pm 3.6^{* * *}$ & $72.0 \pm 10.7$ & $63.1 \pm 25.3$ & $44.0 \pm 6.2$ \\
IL-1 $\beta$ & $116.9 \pm 35.2^{* *}$ & $344.7 \pm 46.4$ & $459.9 \pm 30.7$ & $592.9 \pm 36.7^{* * *}$ \\
IFN- $\gamma$ & $<3.1$ & $37.4 \pm 7.7$ & $33.9 \pm 5.9$ & $31.1 \pm 4.3$ \\
\hline
\end{tabular}

IFN, interferon; IL, interleukin; KC, keratinocyte chemoattractant; TNF, tumor necrosis factor

severity and frequency of exacerbations is not completely understood, however. Recent studies suggest that tiotropium also has direct anti-inflammatory effects (Arai et al., 2010; Cui et al., 2010; Wollin and Pieper, 2010). Therefore, the positive effects of tiotropium on exacerbations in COPD patients may be due to the direct reduction of bronchoconstriction, its anti-inflammatory properties, or a combination of both.

We investigated whether tiotropium has anti-inflammatory and bronchoprotective effects in mice, in which inflammation and bronchoconstriction are triggered by a combination of CS exposure and infection with either H1N1 or RSV in novel models for COPD exacerbation. We found that tiotropium suppressed the reduction in lung function induced by CS and the H1N1 infection, confirming its bronchoprotective effect. Furthermore, numbers of neutrophils and macrophages were also significantly reduced in the tiotropium-treated mice.
Both neutrophil and macrophage numbers are increased in the lungs of patients with COPD; in particular, neutrophils are further increased during exacerbations (Wedzicha and Seemungal, 2007). It has been suggested that they may contribute to or cause the symptoms of exacerbations (Papi et al., 2006). Thus, lowering the influx of these inflammatory cells to the lungs may contribute to the positive effect of tiotropium on exacerbations. In addition, tiotropium also dose-dependently decreased IL- 6 and IFN- $\gamma$ levels in airways. Both inflammatory mediators are increased in COPD patients, and levels peak during exacerbations (Barnes, 2008). A clinical study previously linked significantly higher amounts of IL-6 in sputum of COPD patients to viral-induced exacerbations and airway obstruction (Rohde et al., 2008). Furthermore, in murine studies, IFN- $\gamma$ was associated with the development of emphysema, a further hallmark of severe COPD in patients (Kang et al., 2006). Consistent with our findings, Wollin and
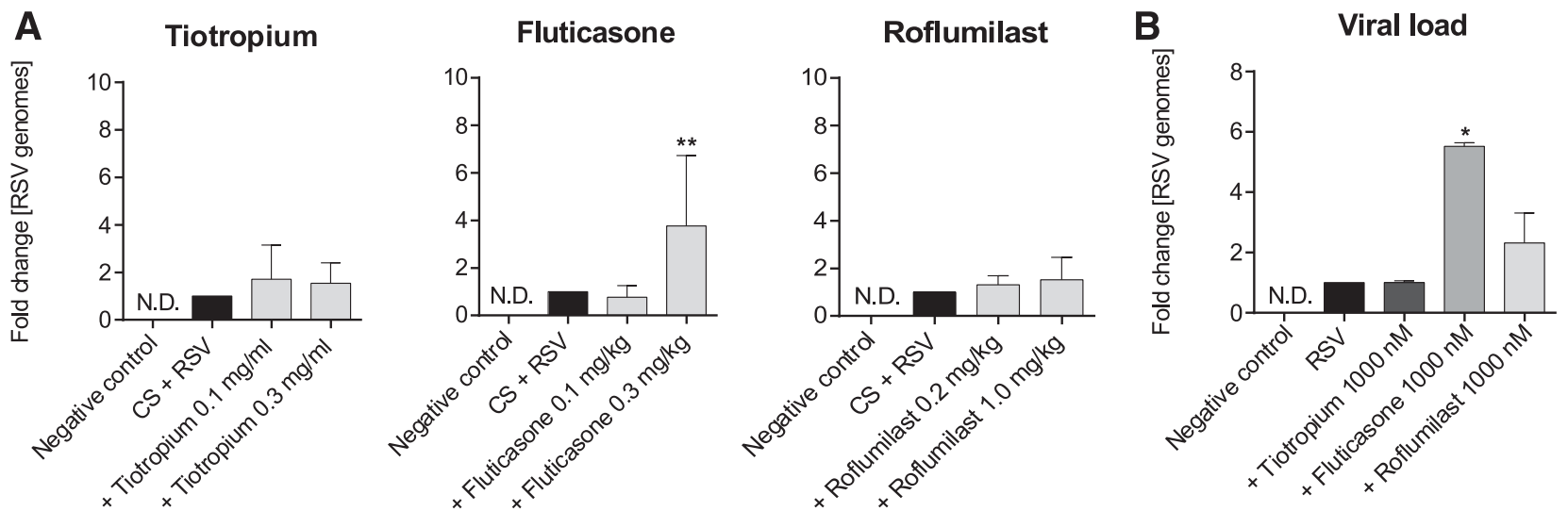

Fig. 7. Amount of RSV in vivo and in vitro. (A) Mice were treated as described in Fig. 6 . The viral load in lung homogenate was determined (mean \pm S.E.M. from $n=4-8$ animals per group). (B) NCI-H292 cells were infected with RSV and treated with 10, 100, or 1000 nM tiotropium, fluticasone, or roflumilast. The amount of virus was measured in the cell lysates. Mean \pm S.E.M. of four separate wells is shown. $* * * P<$ $0.0001, * * * P<0.001, * * P<0.01$, and $* P<0.05$ represent significant differences compared with the CS-exposed and H1N1-infected group or the $\mathrm{H} 1 \mathrm{~N}$-infected cells. 
ChAT

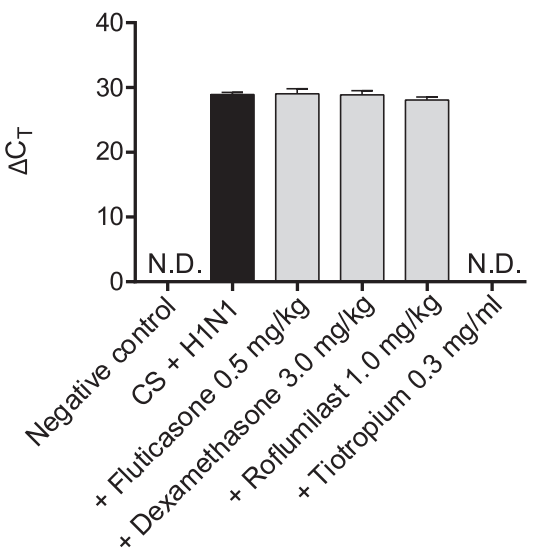

NANS

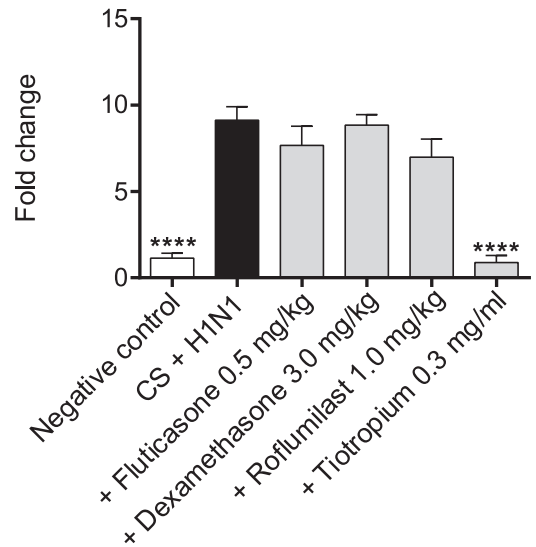

Fig. 8. ChAT and NANS expression in CS-exposed and H1N1-infected mice after treatment with dexamethasone, fluticasone, roflumilast, or tiotropium. Mice were exposed to CS and infected with H1N1 and additionally treated with dexamethasone $(3.0 \mathrm{mg} / \mathrm{kg})$, fluticasone $(0.5 \mathrm{mg} / \mathrm{kg})$, roflumilast $(1.0 \mathrm{mg} / \mathrm{kg})$, or tiotropium $(0.3 \mathrm{mg} / \mathrm{ml})$. Changes in RNA levels of ChAT and NANS are illustrated by $\Delta \mathrm{C}_{\mathrm{T}}$ values or as fold change normalized to $18 \mathrm{~S}$ rRNA. Mean values \pm S.E.M. of $n=$ 4-8 animals per group are shown. ${ }^{* * * *} P<0.0001$, $* * * P<$ $0.001,{ }^{*} P P<0.01$, and $* P<0.05$ represent significant differences compared with the CS-exposed and H1N1infected group.
Pieper (2010) showed that $0.3 \mathrm{mg} / \mathrm{ml}$ nebulized tiotropium significantly reduced total cells, neutrophils, and cytokines such as IL-6 in the lungs of CS-exposed mice (Wollin and Pieper, 2010). Comparable effects were also observed in our current study, where levels of total cells, neutrophils, and cytokines in the lungs were much higher, indicating an antiinflammatory effect of tiotropium also in an exacerbated disease condition. Our results suggest that, in addition to reducing the numbers of neutrophils, tiotropium may reduce the frequency and severity of exacerbations by lowering the production of IL- 6 and IFN- $\gamma$ in the lungs of patients. Currently, we can only hypothesize through which downstream mechanisms exactly tiotropium mediates the antiinflammatory effects we have detected in our exacerbation models; however, we found that tiotropium downregulates the mRNA expression of ChAT, and NANS in the lungs of $\mathrm{CS} / \mathrm{H} 1 \mathrm{~N} 1$-challenged mice. ChAT is the synthesizing enzyme of acetylcholine, and both are ubiquitously expressed throughout the airways and furthermore are involved in inflammatory processes and remodeling partly independent of M3 receptor signaling (Racke and Matthiesen, 2004; Gosens et al., 2006; Racke et al., 2006; Kolahian and Gosens, 2012). Therefore, a reduction in ChAT expression leading to a reduction in acetylcholine, due to tiotropium treatment, might explain in part some of the observed antiinflammatory features. In addition, we found that NANS expression, upregulated in the lung of CS/H1N1-treated mice, was significantly reduced in the tiotropium-treated mice. NANS is an important enzyme for the biosynthesis of sialic acid, a receptor for influenza virus (Sauter et al., 1992; Lawrence et al., 2000). Therefore, reduced NANS expression could result in a reduction of sialic acid, thereby attenuating viral entry, which in turn could result in less replication, a reduced viral load, and thereby less inflammation. Supporting this view is the finding that we found H1N1 load significantly reduced in our CS/H1N1 model on treatment with tiotropium. The finding that tiotropium might directly reduce viral load is supported by further in vitro studies (Iesato et al., 2008). Further studies evaluating through which mechanism tiotropium reduces inflammation during viral exacerbations are warranted. Our studies suggest that tiotropium may have this effect by either reducing inflammation directly or by reducing viral entry/load, leading to less inflammation.
We also investigated the effects of fluticasone on CS/H1N1induced inflammation. In contrast to tiotropium, fluticasone increased the amount of IL- $6, \mathrm{KC}, \mathrm{TNF}-\alpha$, and IFN- $\gamma$ in the airways, failed to reduce total cell, neutrophil or macrophage numbers in the lung, worsened lung function, and increased body weight loss in mice exposed to CS and infected with H1N1. The amplified inflammation might be responsible for the increased decline in lung function observed in this study. In addition, an increased destruction of epithelia was observed in the airways upon treatment of CS-exposed and H1N1-infected mice with fluticasone. In support of our findings are the results of a recent study linking fluticasone treatment to the induction of epithelial injury and altered epithelial barrier function (MacRedmond et al., 2014). The altered epithelial barrier upon treatment with fluticasone might also explain in part the increased viral load as it may facilitate viral distribution in the tissue. These findings suggest that ICS treatment, in particular with fluticasone, the major ICS being used to treat COPD, might increase the viral burden and the amount of inflammatory cytokines in patients. Moreover, it might explain the increased risk for pneumonia in COPD patients upon ICS treatment (Calverley et al., 2007; Singh et al., 2009) and supports the finding that many COPD patients do not benefit from ICS treatment (Barnes, 2004, 2013)

It remains to be elucidated whether other ICS (e.g., budesonide, mometasone, ciclesonide, or fluticasone furoate) have the same effects as fluticasone. Interestingly, the increase in viral load both in the CS/H1N1-infected mice and the NCI-H292 cells was also observed when applying dexamethasone, strongly suggesting that the increase in viral load is not fluticasone-specific but due to the general mode of action of steroids. In contrast to fluticasone, dexamethasone-treated mice exhibited a reduction in some pro-inflammatory cytokines in the lungs. Dexamethasone treatment also did not worsen or reduce lung function but, similar to fluticasone, increased the loss of body weight.

Another therapy available to COPD patients is treatment with roflumilast (Rabe, 2011; Oba and Lone, 2013). We tested roflumilast in the CS/H1N1 model and found that the drug reduced macrophage numbers, IL- 6 , and $\mathrm{KC}$ in the lung but had no significant effect on neutrophil numbers or lung function. Viral load in the animals and in NCI-H292 cells 
and loss of body weight were also unaffected by roflumilast. These results illustrate the anti-inflammatory properties of roflumilast on COPD-associated inflammatory parameters such as IL-6 and the murine IL- 8 homologue KC. The reduction in inflammation might explain the reduced rate of exacerbations in some patients treated with the drug (Rennard et al., 2011); however, the risk-to-benefit ratio of roflumilast is still under debate (Oba and Lone, 2013).

Exacerbations in COPD patients are caused by different viruses (Sapey and Stockley, 2006). For this reason, we wanted to test the effects of different drugs in an additional model of COPD exacerbation using a different virus. For this purpose, we developed an CS-exposure and RSV-infection mouse model of COPD exacerbation. We used an RSV reinfection protocol because this yielded a more robust exacerbation phenotype compared with a single infection (data not shown). Furthermore, humans are often re-infected with RSV because, similar to mice, humans do not generate a protective memory response against RSV (Singleton et al., 2003; Collins and Graham, 2008). Compared with the CS/H1N1exacerbation model, the inflammatory response in the $\mathrm{CS} /$ RSV model was weaker, and no impairment of lung function was measurable. Nevertheless, tiotropium again reduced the pro-inflammatory mediators IL-6, IFN- $\gamma$, and TNF- $\alpha$ and neutrophil numbers in the lung significantly, without affecting the loss in body weight or the viral load in the lung. In contrast, fluticasone significantly increased the amount of $\mathrm{KC}$ and the amount of virus in the lung and increased loss of body weight but had no effect on neutrophil numbers. Although roflumilast showed some suppressive effects in the CS/H1N1 model, no anti-inflammatory effects were detected in the CS/RSV model. Roflumilast treatment also did not impact the viral load but led to a slight increase in the loss of body weight. Taken together, again, tiotropium was superior in inhibiting inflammatory responses induced by RSV and CS compared with fluticasone and roflumilast. Fluticasone, similar to the CS/H1N1 experiments, increased the RSV load in the lung, an effect also observed in cell cultures using bronchial epithelial cells infected with RSV and treated with fluticasone. Tiotropium or roflumilast had no effect on the RSV load in the NCI-H292 cells.

In conclusion, we found that tiotropium has anti-inflammatory effects on both CS/H1N1- and CS/RSV-induced inflammation in mice without increasing viral load or inducing body weight loss. Our findings are in line with previous reports showing anti-inflammatory effects of tiotropium in vivo and in vitro and show that M3 muscarinic receptor signaling contributes to inflammation (Arai et al., 2010; Wollin and Pieper, 2010; Karakiulakis and Roth, 2012). Surprisingly, the observed anti-inflammatory effects were superior to those of roflumilast and fluticasone. Fluticasone was not only inferior to tiotropium but also increased viral load and body weight loss in both CS/ H1N1 and CS/RSV exacerbation models. Our data support the view that the positive effect of tiotropium on exacerbation rates can be partly attributed to its anti-inflammatory activity.

\section{Acknowledgments}

The authors thank Benjamin Strobel and Eva Wex for the support with the qPCR experiments and scientific support and Mathilde Borsch for the excellent technical assistance.

\section{Authorship Contribution}

Participated in research design: Bucher, Duechs, Tilp, Jung, Erb. Conducted experiments: Bucher, Duechs, Tilp.

Performed data analysis: Bucher, Duechs, Tilp, Jung, Erb.

Wrote or contributed to the writing of the manuscript: Bucher, Jung, Erb.

\section{References}

Arai N, Kondo M, Izumo T, Tamaoki J, and Nagai A (2010) Inhibition of neutrophil elastase-induced goblet cell metaplasia by tiotropium in mice. Eur Respir $J$ 35: 1164-1171.

Asano K, Shikama Y, Shibuya Y, Nakajima H, Kanai K, Yamada N, and Suzaki H (2008) Suppressive activity of tiotropium bromide on matrix metalloproteinase production from lung fibroblasts in vitro. Int $J$ Chron Obstruct Pulmon Dis 3: 781-789.

Barnes PJ (2002) New treatments for COPD. Nat Rev Drug Discov 1:437-446.

Barnes PJ (2004) Corticosteroid resistance in airway disease. Proc Am Thorac Soc 1: 264-268.

Barnes PJ (2013) Corticosteroid resistance in patients with asthma and chronic obstructive pulmonary disease. J Allergy Clin Immunol 131:636-645.

Barnes PJ (2008) The cytokine network in asthma and chronic obstructive pulmonary disease. J Clin Invest 118:3546-3556.

Bateman ED, Rennard S, Barnes PJ, Dicpinigaitis PV, Gosens R, Gross NJ, Nadel JA, Pfeifer M, Racké K, and Rabe KF, et al. (2009) Alternative mechanisms for tiotropium. Pulm Pharmacol Ther 22:533-542.

Bos IS, Gosens R, Zuidhof AB, Schaafsma D, Halayko AJ, Meurs H, and Zaagsma J (2007) Inhibition of allergen-induced airway remodelling by tiotropium and budesonide: a comparison. Eur Respir $J$ 30:653-661.

Bosnjak B, Tilp C, Tomsic C, Dekan G, Pieper MP, Erb KJ, and Epstein MM (2014) Tiotropium bromide inhibits relapsing allergic asthma in BALB/c mice. Pulm Pharmacol Ther 27:44-51.

Buels KS, Jacoby DB, and Fryer AD (2012) Non-bronchodilating mechanisms of tiotropium prevent airway hyperreactivity in a guinea-pig model of allergic asthma. Br J Pharmacol 165:1501-1514.

Bühling F, Lieder N, Kühlmann UC, Waldburg N, and Welte T (2007) Tiotropium suppresses acetylcholine-induced release of chemotactic mediators in vitro. Respir Med 101:2386-2394.

Calverley PM, Anderson JA, Celli B, Ferguson GT, Jenkins C, Jones PW, Yates JC, and Vestbo J; TORCH investigators (2007) Salmeterol and fluticasone propionate and survival in chronic obstructive pulmonary disease. N Engl J Med 356:775-789.

Collins PL and Graham BS (2008) Viral and host factors in human respiratory syncytial virus pathogenesis. J Virol 82:2040-2055.

Crim C, Pierre LN, and Daley-Yates PT (2001) A review of the pharmacology and pharmacokinetics of inhaled fluticasone propionate and mometasone furoate. Clin Ther 23:1339-1354.

Cui Y, Devillier P, Kuang X, Wang H, Zhu L, Xu Z, Xia Z, Zemoura L, Advenier C, and Chen $\mathrm{H}$ (2010) Tiotropium reduction of lung inflammation in a model of chronic gastro-oesophageal reflux. Eur Respir $J$ 35:1370-1376.

Dance A (2012) Health impact: breathless. Nature 489:S2-S3.

Disse B, Speck GA, Rominger KL, Witek TJ, Jr, and Hammer R (1999) Tiotropium (Spiriva): mechanistical considerations and clinical profile in obstructive lung disease. Life Sci 64:457-464

Duechs MJ, Tilp C, Tomsic C, Gantner F, and Erb KJ (2014) Development of a novel severe triple allergen asthma model in mice which is resistant to dexamethasone and partially resistant to TLR7 and TLR9 agonist treatment. PLoS One 9:e91223.

Gosens R, Bos IS, Zaagsma J, and Meurs H (2005) Protective effects of tiotropium bromide in the progression of airway smooth muscle remodeling. Am J Respir Crit Care Med 171:1096-1102.

Gosens R, Zaagsma J, Meurs H, and Halayko AJ (2006) Muscarinic receptor signaling in the pathophysiology of asthma and COPD. Respir Res 7:73.

Hamelmann E, Schwarze J, Takeda K, Oshiba A, Larsen GL, Irvin CG, and Gelfand EW (1997) Noninvasive measurement of airway responsiveness in allergic mice using barometric plethysmography. Am J Respir Crit Care Med 156:766-775.

Hatzelmann A and Schudt C (2001) Anti-inflammatory and immunomodulatory potential of the novel PDE4 inhibitor roflumilast in vitro. J Pharmacol Exp Ther 297: $267-279$.

Iesato K, Tatsumi K, Saito K, Ogasawara T, Sakao S, Tada Y, Kasahara Y, Kurosu K, Tanabe N, and Takiguchi Y, et al. (2008) Tiotropium bromide attenuates respiratory syncytial virus replication in epithelial cells. Respiration 76:434-441.

Jeffery PK (2000) Comparison of the structural and inflammatory features of COPD and asthma. Giles F. Filley Lecture. Chest 117(5, Suppl 1):251S-260S.

Kang MJ, Lee CG, Cho SJ, Homer RJ, and Elias JA (2006) IFN-gamma-dependent DNA injury and/or apoptosis are critical in cigarette smoke-induced murine emphysema. Proc Am Thorac Soc 3:517-518.

Karakiulakis G and Roth M (2012) Muscarinic receptors and their antagonists in COPD: anti-inflammatory and antiremodeling effects. Mediators Inflamm 2012 : 409580.

Keam SJ and Keating GM (2004) Tiotropium bromide: a review of its use as maintenance therapy in patients with COPD. Treat Respir Med 3:247-268.

Kolahian S and Gosens R (2012) Cholinergic regulation of airway inflammation and remodelling. J Allergy (Cairo) 2012:681258.

Lawrence SM, Huddleston KA, Pitts LR, Nguyen N, Lee YC, Vann WF, Coleman TA and Betenbaugh MJ (2000) Cloning and expression of the human $\mathrm{N}$-acetylneuraminic acid phosphate synthase gene with 2-keto-3-deoxy-D-glycero- D-galacto-nononic acid biosynthetic ability. J Biol Chem 275:17869-17877.

MacRedmond RE, Singhera GK, Wadsworth SJ, Attridge S, Bahzad M, Williams K, Coxson HO, White SR, and Dorscheid DR (2014) Fluticasone induces epithelial injury and alters barrier function in normal subjects. J Steroids Horm Sci 5:5. 
Magnussen H, Disse B, Rodriguez-Roisin R, Kirsten A, Watz H, Tetzlaff K, Towse L, Finnigan H, Dahl R, and Decramer M, et al.; WISDOM Investigators (2014) Withdrawal of inhaled glucocorticoids and exacerbations of COPD. $N$ Engl J Med 371:1285-1294.

Mamary AJ and Criner GJ (2009) Tiotropium bromide for chronic obstructive pulmonary disease. Expert Rev Respir Med 3:211-220.

Mohamed Hoesein FA, Zanen P, de Jong PA, van Ginneken B, Boezen HM, Groen HJ, Oudkerk M, de Koning HJ, Postma DS, and Lammers JW (2013) Rate of progression of CT-quantified emphysema in male current and ex-smokers: a follow-up study. Respir Res 14:55.

Mundy C and Kirkpatrick P (2004) Tiotropium bromide. Nat Rev Drug Discov 3 : 643-644.

Oba Y and Lone NA (2013) Efficacy and safety of roflumilast in patients with chronic obstructive pulmonary disease: a systematic review and meta-analysis. Ther $A d v$ Respir Dis 7:13-24.

Ohta S, Oda N, Yokoe T, Tanaka A, Yamamoto Y, Watanabe Y, Minoguchi K, Ohnishi T, Hirose T, and Nagase H, et al. (2010) Effect of tiotropium bromide on airway inflammation and remodelling in a mouse model of asthma. Clin Exp Allergy 40 1266-1275.

Papi A, Luppi F, Franco F, and Fabbri LM (2006) Pathophysiology of exacerbations of chronic obstructive pulmonary disease. Proc Am Thorac Soc 3:245-251.

Park HY, Man SF, and Sin DD (2012) Inhaled corticosteroids for chronic obstructive pulmonary disease. BMJ 345:e6843.

Rabe KF (2011) Update on roflumilast, a phosphodiesterase 4 inhibitor for the treatment of chronic obstructive pulmonary disease. Br J Pharmacol 163:53-67.

Rabe KF, Hurd S, Anzueto A, Barnes PJ, Buist SA, Calverley P, Fukuchi Y, Jenkins $\mathrm{C}$, Rodriguez-Roisin R, and van Weel C, et al.; Global Initiative for Chronic Obstructive Lung Disease (2007) Global strategy for the diagnosis, management, and prevention of chronic obstructive pulmonary disease: GOLD executive summary. Am J Respir Crit Care Med 176:532-555.

Racké K, Juergens UR, and Matthiesen S (2006) Control by cholinergic mechanisms. Eur J Pharmacol 533:57-68.

Racké K and Matthiesen S (2004) The airway cholinergic system: physiology and pharmacology. Pulm Pharmacol Ther 17:181-198.

Rennard SI, Calverley PM, Goehring UM, Bredenbröker D, and Martinez FJ (2011) Reduction of exacerbations by the PDE4 inhibitor roflumilast-the importance of defining different subsets of patients with COPD. Respir Res 12:18.

Rich A (2005) Corticosteroids and chronic obstructive pulmonary disease in the nursing home. J Am Med Dir Assoc 6 (3, Suppl)S68-S74.

Rodríguez-Roisin R (2006) COPD exacerbations. 5: management. Thorax 61:535-544.
Rohde G, Borg I, Wiethege A, Kauth M, Jerzinowski S, An Duong Dinh T, Bauer TT, Bufe A, and Schultze-Werninghaus G (2008) Inflammatory response in acute viral exacerbations of COPD. Infection 36:427-433.

Sapey E and Stockley RA (2006) COPD exacerbations. 2: aetiology. Thorax 61: $250-258$

Sauter NK, Hanson JE, Glick GD, Brown JH, Crowther RL, Park SJ, Skehel JJ, and Wiley DC (1992) Binding of influenza virus hemagglutinin to analogs of its cell-surface receptor, sialic acid: analysis by proton nuclear magnetic resonance spectroscopy and X-ray crystallography. Biochemistry 31:9609-9621.

Singh S, Amin AV, and Loke YK (2009) Long-term use of inhaled corticosteroids and the risk of pneumonia in chronic obstructive pulmonary disease: a meta-analysis. Arch Intern Med 169:219-229.

Singleton R, Etchart N, Hou S, and Hyland L (2003) Inability to evoke a long-lasting protective immune response to respiratory syncytial virus infection in mice correlates with ineffective nasal antibody responses. $J$ Virol 77:11303-11311.

Stockley RA, Mannino D, and Barnes PJ (2009) Burden and pathogenesis of chronic obstructive pulmonary disease. Proc Am Thorac Soc 6:524-526.

Suzaki I, Asano K, Shikama Y, Hamasaki T, Kanei A, and Suzaki H (2011) Suppression of IL-8 production from airway cells by tiotropium bromide in vitro. Int $J$ Chron Obstruct Pulmon Dis 6:439-448.

Tashkin DP, Celli B, Senn S, Burkhart D, Kesten S, Menjoge S, and Decramer M; UPLIFT Study Investigators (2008) A 4-year trial of tiotropium in chronic obstructive pulmonary disease. $N$ Engl J Med 359:1543-1554.

van der Velden VH (1998) Glucocorticoids: mechanisms of action and anti-inflammatory potential in asthma. Mediators Inflamm 7:229-237.

Vogelmeier C, Hederer B, Glaab T, Schmidt H, Rutten-van Mölken MP, Beeh KM, Rabe KF, and Fabbri LM; POET-COPD Investigators (2011) Tiotropium versus salmeterol for the prevention of exacerbations of COPD. $N$ Engl J Med 364: 1093-1103.

Wedzicha JA and Seemungal TA (2007) COPD exacerbations: defining their cause and prevention. Lancet 370:786-796.

Wollin L and Pieper MP (2010) Tiotropium bromide exerts anti-inflammatory activity in a cigarette smoke mouse model of COPD. Pulm Pharmacol Ther 23:345-354.

Address correspondence to: Prof. Dr. Klaus J. Erb, Immunology \& Respiratory Diseases Research, Boehringer Ingelheim Pharma GmbH \& Co. KG, Birkendorfer Straße 65, 88400 Biberach an der Riss, Germany, E-mail: klaus.erb@boehringer-ingelheim.com 